\title{
Threats and Conservation Strategies on Urban Wetlands: A Case of Monavale and Surrounding Areas in Harare, Zimbabwe
}

\author{
Silipiwe Sharai ${ }^{*}$, Tarakini Tawanda, Chibememe Gladman \\ Department of Wildlife Ecology and Conservation, Chinhoyi University of Technology, Chinhoyi, Zimbabwe \\ Email address: \\ ssilipiwe@gmail.com (S. Sharai), ttarakini@cut.ac.zw (T. Tawanda), gchibememe15@gmail.com (C. Gladman) \\ ${ }^{*}$ Corresponding author
}

\section{To cite this article:}

Silipiwe Sharai, Tarakini Tawanda, Chibememe Gladman. Threats and Conservation Strategies on Urban Wetlands: A Case of Monavale and Surrounding Areas in Harare, Zimbabwe. American Journal of Environmental Protection. Vol. 9, No. 2, 2020, pp. 31-38.

doi: 10.11648/j.ajep.20200902.12

Received: April 20, 2020; Accepted: May 5, 2020; Published: May 27, 2020

\begin{abstract}
Wetlands are valuable ecosystems on which humans depend through the utilisation of the ecological goods and services including water for domestic and commercial use. Until recently, efforts on wetland conservation have shifted to community participation since they are important stakeholders in using wetland resources. This study solicited local people's perceptions on 1) threats to the Monavale wetland (Harare, Zimbabwe), 2) the conservation strategies they perceive most appropriate and 3) the likely consequences of losing this wetland. The study used 80 household questionnaires that were administered to four suburbs (representing three wards) surrounding Monavale, with respondents having different sociodemographic variables (age, ward, employment status and education level). Chi-square tests were used to test for associations between perceived threats across all variables. Multiple Correspondence Analysis was performed to explore relationships between respondents' socio-demographic variables with 1) goods and services, and 2) perceived consequences of losing Monavale wetland. Main threats cited were agriculture and housing development projects (43 and 36\% of respondents respectively). People from wards 5 and 7 cited mostly socio-economic whilst ward 16 cited ecological related goods and services. The respondents' age was associated with perceptions towards the threats facing Monavale wetland $\left(\chi^{2}=31.563\right.$, d. $\mathrm{f}=12, P=0.002)$. Respondents cited 5 pieces of legislation with Environmental Management Act being the most $(75 \%$ of respondents) which they think could be better implemented if wetland conservation is to be achieved. The study concludes that, there is need to integrate all relevant stakeholders in wetland conservation for effective legislation implementation as well as increasing educational awareness to both communities and policy makers.
\end{abstract}

Keywords: Wetlands, Communities, Goods and Services, Threats, Conservation Strategies, Management, Legislation

\section{Introduction}

The value of wetlands including their significance to biodiversity, scientific explorations, climate regulation, tourism and socio-cultural importance should be used in raising awareness with decision-makers especially in developmental projects $[11,1]$. Although many of the threats facing global wetlands are rooted in poverty and high demographic growth rates [9], it is often the case of neglecting or underestimating the value of conserving wetlands and poor implementation of conservation policies that are leading to their loss and degradation [26]. Also, until recently, wetlands had poor legal and policy mechanisms being implemented to assure their conservation and sustainable use $[26,2]$. Urban wetlands particularly in developing countries are threatened by catchment developments (industrial areas and urban housing), agricultural activities that alter the ecosystems goods and services they can offer [24]. It is therefore imperative that conservationists evaluate human perceptions of such alterations and their ideas to solve the challenges.

Wetlands in Africa occupy approximately 7\% [4]. These wetlands directly support the livelihoods of millions of people. Sustainable management of wetlands is therefore 
critical to the long-term health, safety and welfare of many African communities [25]. Wetlands are being modified or reclaimed, often driven strongly by economic motives. In Southern Africa, it has been especially noted that wetland users and decision-makers have insufficient understanding of the consequences of alternative management and policy regimes on wetland functioning, ecosystem services and human well-being [10]. In addition, the array of challenges surrounding wetland conservation is directly or indirectly linked to either community trying to improve their well-being or by lack of different stakeholders' participation which compromise wise use of wetlands [22]. Management systems constituting of regulatory stakeholders, governance system and the available legislation are necessary to allow decision makers in making suitable interventions towards the sustainability of wetland resources. The local communities around wetlands should also be aware of the legislation systems and be involved in the decision making process so as to bridge the awareness gap that exists.

Zimbabwe has been experiencing a progressive loss of wetlands [16, 14]. Ignorance concerning the ecological importance of wetlands is evident among the Zimbabwean citizens [21]. Monavale vlei, located in Harare is one of Zimbabwe's seven Ramsar sites. It is a headwater wetland harbouring many taxa of living organisms such as amphibians (e.g. Common River Frog Rana angolensis), reptiles (e.g. Leopard Tortoise Geochelone pardalis), waterbirds (e.g. African Pygmy Goose Nettapus auritus, Grey heron Ardea cinerea) that are critical to its ecosystem functioning [29]. The wetland is governed by Harare City Council whilst the Zimbabwean Environmental Management Agency (EMA) regulates the activities by making use of the Ramsar policies. However, the wetland is threatened by human activities including property developments, urban agriculture and siltation [22].
As wetlands are often large open spaces left in the city, they are attractive sites for developmental projects. For example in Harare, the Chinese shopping mall built in the year 2013 was constructed in contradiction to the provisions of the Zimbabwean Environmental Management Agency (EMA) [3]. In addition, in the year 2015, the City council proposed 160 cluster houses to be built in Monavale vlei despite it being internationally protected [13]. This pressure on wetlands as conceptualized in this study; exist despite the existing laws that are meant to protect them [31]. Seasonal wetland utilisation for small and large scale urban agriculture is destructive to the ecosystem and results in biodiversity loss in wetlands [23].

There have been attempts to raise awareness of the importance of wetlands in Zimbabwe [14]. However, there has been little effort made to evaluate the effects of such awareness campaigns on the people living in and close to these wetlands. Therefore, this study seeks to solicit local people's perceptions on threats to the Harare urban wetlands, using Monavale as a case study. As wetlands are threatened ecosystems, the efforts of wetlands management and conservation has shifted to community participation since they are important stakeholders in using wetland resources [6]. This study therefore focused on assessing how local people with various socio-demographic variables (age, education level, ward, and employment status) perceive threats to Monavale wetland and the conservation strategies that can be best applied to conserve them. We hypothesised that perceptions of people are strongly influenced by their level of education and employment status. We also thought that the distance from wetlands would also influence local people's perceptions; hence perceptions would vary with respondent's ward. The local people's perceptions on consequences of losing Monavale wetland are hypothesised to be more inclined to socio-economic rather than ecological factors.

\section{Materials and Methods}

\subsection{Study Area}

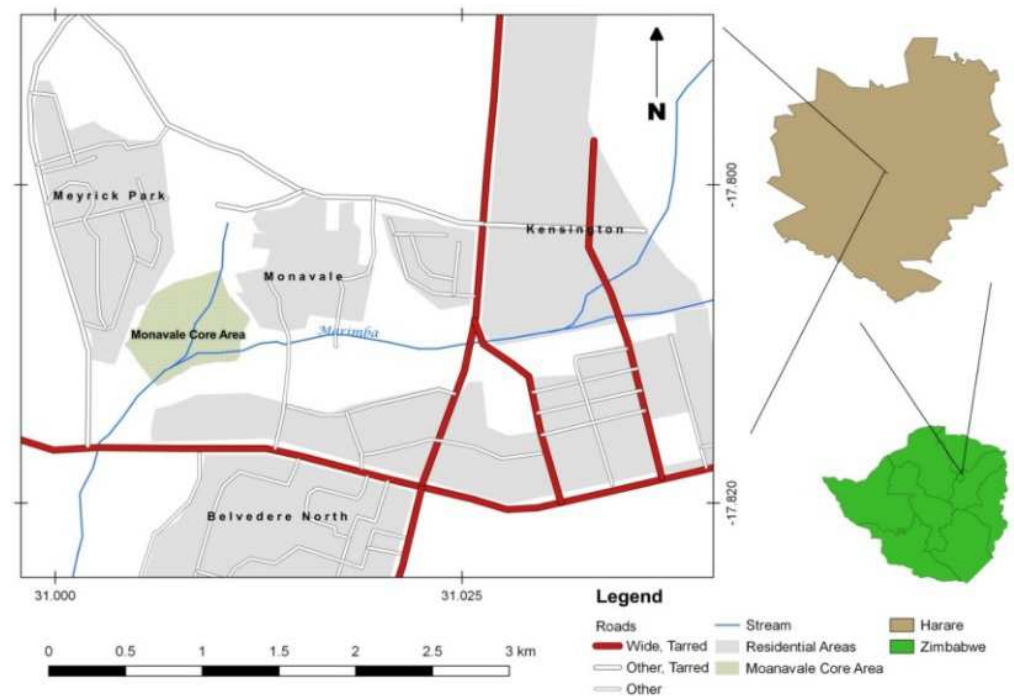

Figure 1. Location of Monavale wetland in relationship to surrounding areas in Harare, Zimbabwe. 
The study was conducted in urban suburbs around Monavale vlei, which is a 40 hectare wetland located between latitude $17^{\circ} 48^{\prime} 0.20^{\prime \prime} \mathrm{S}$ and $17^{\circ} 48^{\prime} 59.0^{\prime \prime} \mathrm{S}$ and longitude $31^{\circ} 00^{\prime} 24.8^{\prime \prime} \mathrm{E}$ and $31^{\circ} 00^{\prime} 50.4^{\prime \prime} \mathrm{E}$ in the Mabelreign district of Harare, Zimbabwe. It is bound by Avondale stream to the south, Marimba stream to the west and Fenella Drive to the east, as shown in Figure 1, and it is administratively under the jurisdiction of the City of Harare. Monavale suburb and Belvedere North are in ward 5 while Kensington and Meyrick Park are in wards 7 and 16. The distance from Monavale wetland to wards 5,7 and 16 is 1,2 and $4 \mathrm{~km}$ respectively.

Harare is characterised by a short wet season, followed by a relatively long dry season. The long-term mean rainfall of the area is about $800 \mathrm{~mm}$ [20]. Early rains are normally received in November, and tend to occur in the form of intense wet spells brought about by the inter-tropical convergence zone [32]. Daily temperatures vary from a minimum of $18^{\circ} \mathrm{C}$ to a maximum of $29^{\circ} \mathrm{C}$ during the wet season, but in the hot and dry season, mean daily temperatures rise to about $25^{\circ} \mathrm{C}$ while day time temperatures can be as high as $35^{\circ} \mathrm{C}$ [29].

Monavale vlei is made up of a calcium carbonate metamorphic parent rock which has a grey appearance, and breaks down into a fine grey powder [29]. The soils therefore support indigenous plant communities dominated by woody plants such as Acacia gerrardii, orchids and aloes. Some of the unique taxa of the vlei include Hydrophila mutica (Swamp weeds) which is endemic to the area, Lannea discolor (Tree grape) which contains some medicinal properties.

Harare City Council is currently struggling to manage the waste under tight budgets; highly inadequate and malfunctioning equipment; inefficient collection practices with variable levels of service, poor and unhygienic operating practices; including unavailability of environmental control systems [33]. This has resulted in increasing rate of indiscriminate illegal waste dumping in Monavale wetland [33].

\subsection{Sampling and Data Collection}

This study used mixed method research where both quantitative and qualitative field approaches were employed as its core scientific methodology. We used purposive sampling to select wards which are close to Monavale wetland, and hence the respondents were thought to be interacting with the wetland. Twenty respondents were selected in each area (Monavale, Meyrick Park, Belvedere North and Kensington), giving a total of 80 respondents. The respondents were randomly chosen, one per household, and the sampling intensity ranged from $9-14 \%$ in each ward.

Semi-structured questionnaires were administered to respondents who were 18 years and above and who had stayed in the area for more than one year. There were 2 versions of the questionnaire, one in English and the second one was translated into Shona (the dominant local language) to cater for respondents who could not use English. The questionnaires were administered between April and June 2018.

The variables included in the interview sought to know the socio-demographic variables: the ward in which the respondent resided, education level (attained up to primary, secondary, or tertiary levels) age (years) and employment status (type of job being done and weather formal or not) of the respondents. The questionnaire adopted a free-list approach to document the known wetlands by respondents in and around the city of Harare. The questions also sought to gain respondents views on goods and services provided by Monavale wetland, the threats it is facing and the perceived consequences of losing Monavale. The questionnaire also enquired respondent knowledge of laws and policies governing Monavale wetland, and the conservation strategies that could be applied to stop or alleviate its degradation.

\subsection{Data Sorting, Analysis and Presentation}

The questionnaire responses were first captured in a Microsoft Excel. We conducted a thematic analysis on the responses of goods and services provided by the wetland, consequences of losing the wetland, threats facing the wetland, conservation strategies for Monavale, laws and policies known and other wetlands cited. For the thematic analysis on wetland goods and services, we modified the division level in the Common International Classification of Ecosystem Services (CICES) [7]. Cross-tabulation was then done to assess the distribution of responses. Frequency distribution plots for known wetlands in Harare were made.

Chi-squared tests were used to assess associations between perceived threats on the wetland and consequences of losing Monavale across respondent age, employment status and ward of residence. In the cases of small values of less than 5 in the cross tabulations, the fisher's test of associations was used. The Kruskal wallis test was used to investigate the relationship between number of wetlands known and respondent age. Multiple Correspondence Analysis (MCAs) were performed to investigate the relationship between respondents' perceived goods and services from Monavale wetlands across wards. MCAs were also used to investigate respondent perceived consequences of losing the wetland across employment status, education level and wards. All analysis was done using the $\mathrm{R}$ statistical package, Version 3.4.3 (R Development core team, 2018).

\section{Results}

The ages, employment status, level of education and ward of origin of the respondents used in this study are summarised in Table 1. The Environmental Management Act (EMA) was mostly cited $(75 \%, n=33)$ as the policy helping in the management of Monavale wetland but only 1 respondent knew of the contribution of the Parks and Wildlife Management Act as illustrated by Table 2 . 
Table 1. Summary of socio-demographic variables in the study $(n=80)$.

\begin{tabular}{llllllllll}
\hline \multirow{2}{*}{ Location of residence } & \multicolumn{2}{l}{ Age (years) } & \multicolumn{3}{c}{ Education level } & \multicolumn{2}{c}{ Employment status } \\
\cline { 2 - 10 } & $\mathbf{1 8 - 3 0}$ & $\mathbf{3 1 - 4 0}$ & $\mathbf{4 1 - 5 0}$ & $\mathbf{5 1 +}$ & Primary & Secondary & Tertiary & Formal & Informal \\
\hline Ward 5 & 12 & 7 & 13 & 8 & 2 & 19 & 19 & 28 & 12 \\
Ward 7 & 7 & 6 & 3 & 4 & 2 & 13 & 5 & 13 & 7 \\
Ward 16 & 4 & 8 & 5 & 3 & 2 & 14 & 4 & 12 & 8 \\
Total & 23 & 21 & 21 & 15 & 6 & 46 & 28 & 53 & 27 \\
\hline
\end{tabular}

Table 2. Laws/Policies cited by Respondents.

\begin{tabular}{ll}
\hline Law/Policy known & N (and percentage) \\
\hline EMA & $33(75 \%)$ \\
Harare City Council & $5(11.3 \%)$ \\
Ramsar Act & $4(9 \%)$ \\
Parks and Wildlife Management Act & $1(2 \%)$ \\
Section 93 Zimbabwe constitution & $1(2 \%)$ \\
\hline
\end{tabular}

The services from wetlands perceived by local people were not uniform across the wards. Respondents from wards 7 and 16 cited more services connected to biodiversity conservation, flood prevention and water provision more than those in ward 5 (Figure 2). Axis 1 of Figure 2 accounted for $20.19 \%$ of variation, in which biodiversity conservation, flood prevention and water provision were opposing services of residential area space. The second axis accounted for $17.05 \%$ of variation in which recreation services opposed aesthetic and residential stands. Respondents from Ward 5 were more inclined to recreation and traditional medicine more than those in wards 7 and 16 .

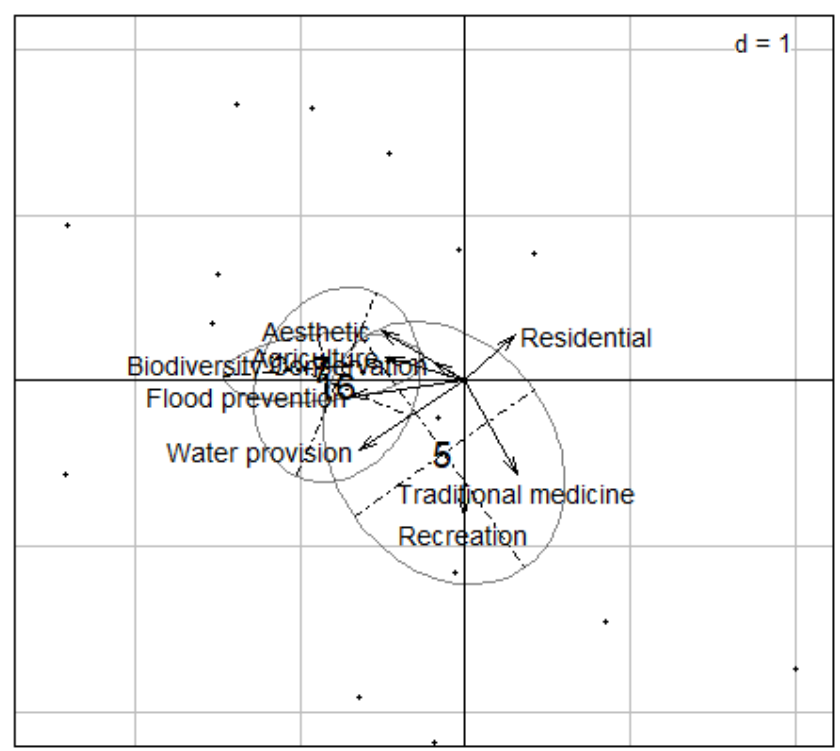

Figure 2. Schematic presentation of perceptions on wetlands goods and services provided by Monavale across wards (represented by the numbers 7 , 16 and 5). The dots represent individual respondents

\subsection{Threats Facing Monavale Wetland}

There was a significant association between age and respondent perceptions towards the threats facing the wetland $\left(\chi^{2}=31.563\right.$, d.f $\left.=12, P=0.002\right)$. Respondents aged between $31-40$ years highlighted that agriculture $(43 \%, n=13)$ and housing development projects $(36 \%, n=9)$ are the main threats to Monavale wetland. However, those aged 18-30 years believed that lack of cooperation among stakeholders in the management is the main threat facing the wetland $(33 \%$, $\mathrm{n}=4$ ). The old people (50 years and above) also cited waste dumping $(56 \%, \mathrm{n}=9)$ in addition to housing development projects.

There was a significant association between communities' perceptions towards threats facing the wetland across wards $\left(\chi^{2}=22.969\right.$, d.f $\left.=8, P=0.003\right)$. Those in Ward 5 and 7 mentioned that housing development projects $(55 \%, \mathrm{n}=21)$ are the main threats facing Monavale wetland, followed by agriculture $(32 \%, \mathrm{n}=12)$ and lack of cooperation among stakeholders $(11 \%, \mathrm{n}=4)$. However, those in Ward 16 also highlighted that burning $(28 \%, \mathrm{n}=7)$ and dumping of waste $(24 \%, n=6)$ are also threats facing the wetland after agriculture $(32 \%, \mathrm{n}=8)$.

In Ward 7 in addition to the issue of shortage of water, the respondents were also concerned with consequences linked to droughts $(26.3 \%, n=5$, Figure $3 A)$. In ward 16 , the shortage of water and biodiversity loss were ranked top ( $31 \%, n=6$ in both cases). There was a significant association between consequences of losing Monavale wetland and employment status (Fishers' Chi-square $P=0.03$ ). Forty percent $(n=16)$ of the formally employed respondents were more concerned about shortage of water, while about $23 \%$ $(n=9)$ were concerned about biodiversity loss. However, those in the informal sector were concerned with drought, in addition to the shortage of water (Figure 3B)

Axis 1 of Figure $3 \mathrm{~A}$ accounted for $25.14 \%$ of variation and the second axis accounted for $20.13 \%$ of variation, with respondents in ward 16 inclined to environmental degradation and flooding. However, this was different to Ward 7 and Ward 5 which had a common concern of shortage of water and aesthetic value loss as a result of losing Monavale wetland. Those in ward 5 were inclined to biodiversity loss whilst those in ward 7 were concerned with disease outbreak. Figure 3B shows that, respondents in the formal employment sector were more concerned with biodiversity loss, aesthetic value loss and environmental degradation. Those who are informally employed were concerned about drought and disease outbreak. However, both wards have a common concern of shortage of water as a consequence of losing the wetland. 


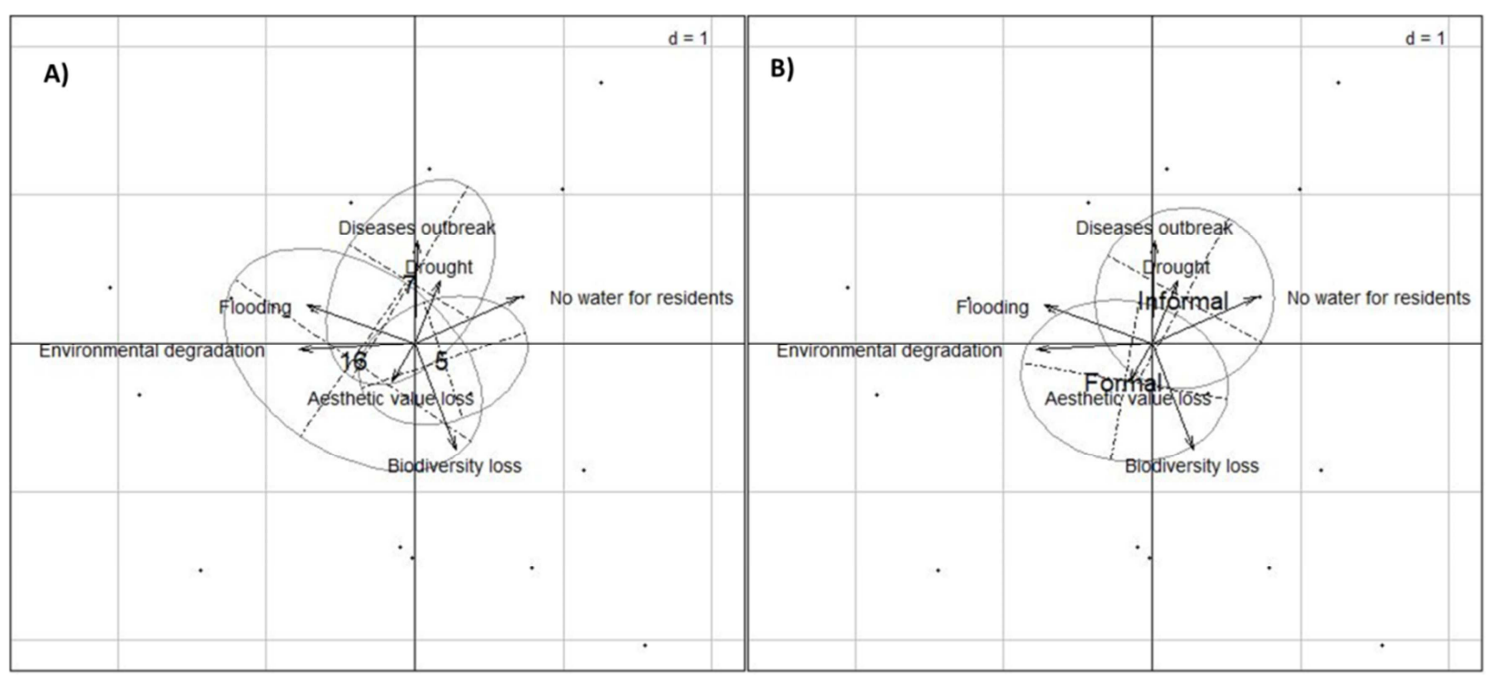

Figure 3. Schematic presentation of consequences of losing Monavale vlei as perceived by the respondents; (A) across wards and (B) across employment status. The dots represent individual respondents.

\subsection{Conservation Strategies for Monavale Wetland}

About $75 \%$ of respondents suggested that implementation of wetland related law and policy is needed for Monavale wetland (Figure 4), whereas 21.2\% recommended educational campaigns. However, a mere $4.5 \%$ of respondents believe that nothing can be done to conserve the
Monavale wetland.

Respondents who have attained secondary education recommend that wetland policy and law implementation is the best solution in order to conserve Monavale wetland $(65 \%, n=20)$, however, about $10 \%$ of respondents were inclined to preservation (Figure 4).

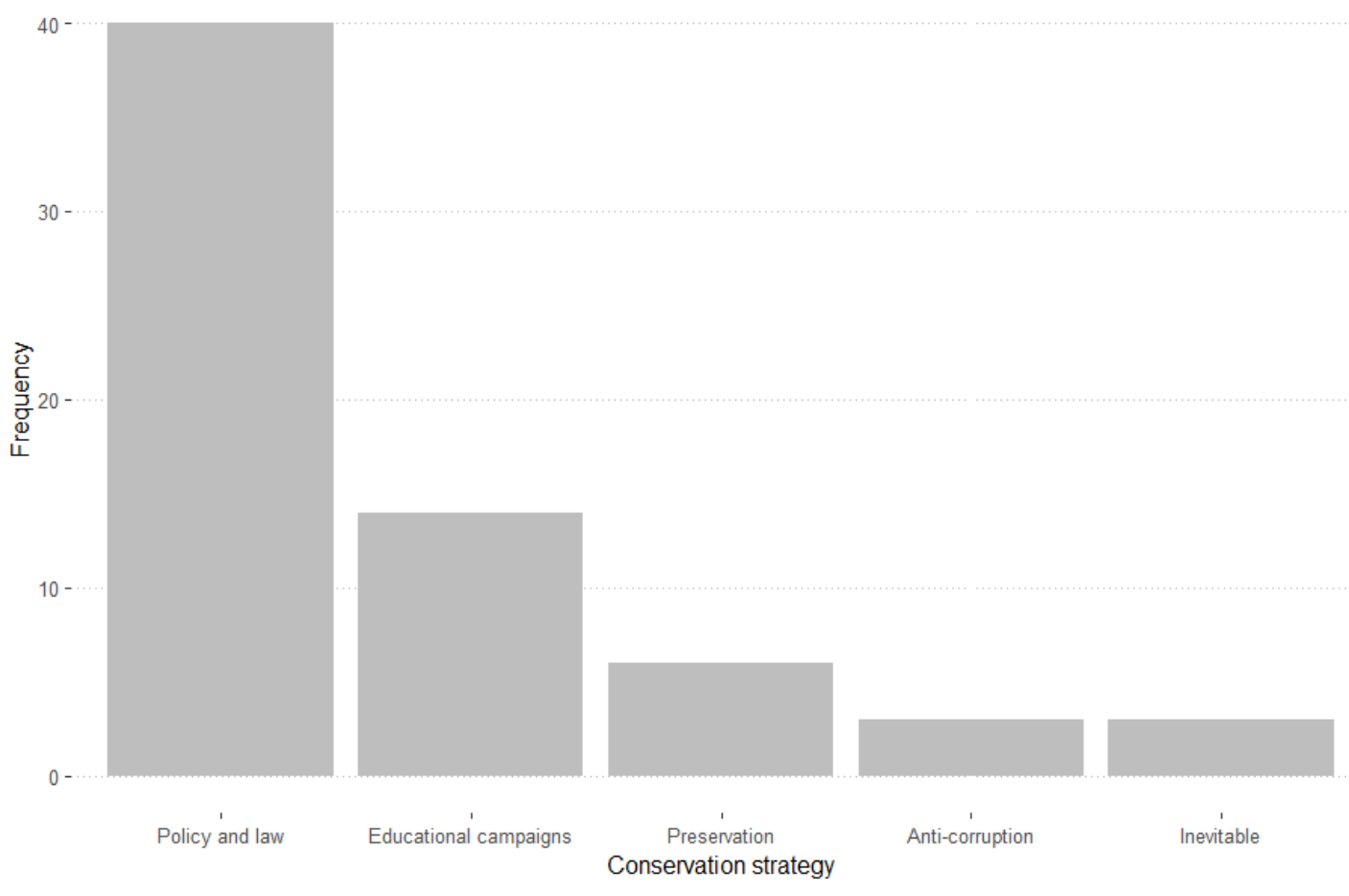

Figure 4. Illustration of suggested conservation strategies by respondents.

\section{Discussion}

\subsection{Respondents' Knowledge of the Wetland}

About 11.3\% mentioned the Harare City Council Act as the policy governing the use of Monavale probably because it is directly involved in decision making on issues in Harare
(Table 2) and specifically its decision on proposing housing projects on Monavale vlei core area [13]. However, only $9 \%$ of the respondents knew of the contribution of Ramsar convention and this can be due to the fact that it has been recently implemented in Zimbabwe. Although findings by Marambanyika and Beckdahl in 2016 suggest that the majority were not aware of the existence and rationale of 
laws governing the use and conservation of the wetlands in communal areas of Zimbabwe, this was not the case for this urban wetland. This could imply that law enforcement in urban areas for environmental issues could be more enforced when compared to rural areas [23].

This study revealed that respondents from Ward 7 and 16 mentioned more of provisioning and regulating services such as flood prevention and biodiversity conservation probably because local people seek various services from wetland ecosystems and thus perceive the value of an ecosystem in relation to its ability to provide the services they desire [5]. Comparatively, respondents from Ward 5 were more inclined to cultural services such as recreational activities and this could be related to their location's proximity to the wetland than those in Ward 7 and 16 and are therefore aware of the actual direct benefits they derive from Monavale wetland. Hartter [8] also found out that resource utilisation and perceptions on ecosystem services may vary with distance to the wetland.

\subsection{Threats Facing Monavale Wetland}

There was a significant association between age and respondent perceptions towards the threats facing the wetland, with the older people (those who were 31 years and above) citing agriculture and development projects while the younger (i.e 18-30 years) only mentioning that lack of cooperation among stakeholders as the main threat facing Monavale wetland. This may be because young people may have encountered negative aspects of Monavale wetland and never experienced a proper "clean environment" since pollution in Harare has been ongoing for over 20 years [18]. This is in line with findings of Shibia, [28] in Marsabit National Reserve in Kenya who found that that there is a general association between age and people's perceptions towards resource use. However, some studies show that there is decrease in youth interest in conservation issues and their perceptions change with age and experience in various occupations [12]. The later could be thought to be driving the perceptions of respondents in this study.

Respondents in wards 5 and 7 had almost similar views of the impacts of housing development projects in the conservation of Monavale wetland. This could be because of their involvement in lobbies to stop constructions that had been proposed on Monavale vlei core area. However, those in ward 16 highlighted that burning and dumping of waste are also threatening the wetland. This may imply that uncontrolled fires and inconsistency in bin collection has forced people to resort to solid waste dumping on empty spaces including wetlands [33]. This is almost similar from the findings by Harter, [8] in Kibale National Park, western Uganda who highlighted that local people's perceptions may be based on information, experiences, knowledge, institutions, and social networks. Our results are in agreement with our hypothesis on the association existing between perceptions of threats facing Monavale wetland and respondent socio-demographic variables.

\subsection{Local People's Priorities for Conservation of Monavale Wetland}

Respondents from Ward 5 mostly cited lack of water for residents, showing that they might be directly benefiting from water provision as also indicated by their preference for goods and services. However, those from Ward 7 considered drinking water shortages and also consequences linked to droughts. This might be because they are the ones who usually depend on provisioning goods and services such as water provision and agriculture. In contrast, respondents from Ward 16 were mainly concerned with ecological consequences such as biodiversity loss and environmental degradation. This only partially conform to the hypothesis of this study that people's perceptions on consequences of losing Monavale wetland are more inclined to socio-economic rather than ecological, because it was only people from wards 5 and 7 who had socioeconomic consequences. The overall relationship that exists across these 3 wards and their perceptions on the consequences of losing the wetland can therefore be directly linked to their views of the goods and services provided by the wetland. However, a study to determine public support on Persina Nature Park (Bulgaria), wetland restoration showed that regulating services are often not considered important because people do not see the end-benefit of such services or how they are relevant in their lives [27].

Both the formally and informally employed respondents were concerned about water shortages, a similar trend is also noted across wards whereby those in ward 5 and 7 are mostly prioritizing water and this could mean that they share common problems associated with water supply in the area. However, those who are formally employed are additionally concerned with biodiversity loss, flooding and environmental degradation whilst those who are informally employed are concerned with disease outbreak, drought and flooding. This could imply that they may have a better understanding of the importance of nature conservation [30] whilst those in the informal sector think of the factors that are directly affects them or their well-being with lesser consideration for biodiversity conservation.

Although not significant, $65 \%$ of respondents who have attained secondary education cited more of wetland related law and policy implementation as a conservation strategy. Similarly, the larger proportion of the respondents who attained tertiary education (57\%) suggested that educational campaigns in addition to law and policy implementation should be the conservation strategy for Monavale wetland. This could have been as a result of the enhanced understanding of the link between regulatory stakeholders and the actual implementation by those who attained higher levels of education [14]. It is however worrying that there were some people who think that it is inevitable to avoid the current Monavale challenges.

\subsection{Perceived Conservation Strategies for Monavale Wetland}

Most the respondents cited the need to implement wetland 
related laws and policies. This could be attributed to gaps in wetlands law and policies that local people observe. Also, the respondents could have noted lack of implementation of laws by responsible institutions when people are encroaching into Monavale wetland or other wetlands in Harare, especially illegal agricultural activities and waste dumping. Other studies also found out that lack of enforcement and implementation measures on wetland-related laws and policies has affected Monavale, and other wetlands in Harare [34, 15]. Mbereko et al, [17] and Matamanda et al., [15] also found out that although the law prohibits agriculture in wetlands, people are still encroaching because there is a lack of clear policy implementation.

Educational campaigns were suggested by only $21 \%$ of the respondents. This might indicate that people perceive missing link of educational awareness to the policy makers possibly because there is no specific national program that is aimed at raising awareness to policy makers [14]. Education might be important because biodiversity could be better managed with the involvement and all relevant stakeholders could be educated. A similar trend has been noted by Mukwindidza [19] in a study conducted in Mutasa District of Zimbabwe, where most respondents cited that stakeholders who are responsible for ensuring that environmental legislation is effectively implemented lacks consistency. Hence, this is in line with the hypothesis that conservation strategies cited by local people suggest more to appropriate authorities compared to them.

\section{Implications for Conservation}

There is need for an adaptive and integrated approach when it comes to urban wetland governance. City of Harare should work hand in hand with other environmental regulatory authorities such as EMA, Birdlife Zimbabwe and Zimbabwe Parks and Wildlife Management Authority and other essential stakeholders such as schools, health clubs, business people around in the governance of biodiversity hotspots to avoid conflicting interests in the management of wetland resources. There is also a need to involve all relevant stakeholders in wetland conservation in Harare. For effective implementation of the laws and policies set for wetland conservation, all relevant stakeholders should be aware and have full participation. For example, since the Conservation Society of Monavale (COSMO), a community based initiative has proved to that communities can play a major role in the protection of wetlands. This could also be done, for other wetlands in Harare which are threatened with development among other threats.

There is a general need for educational campaigns on the importance of wetlands so as deliver biodiversity conservation in the midst of uncontrollable population growth which might exert pressure to available wetland resources.

\section{References}

[1] Berghofer, A. Brown, C. Bruner, A. (2016) 'Increasing the Policy Impact of Ecosystem Service Assessments and Valuations Insights from Practice'.

[2] Biswas, M. Samal. N. R. Ray, P. K. and Mazumdar, A. (2010) 'Human wetland dependency and socio-economic evaluation of wetland functions through participatory approach in rural India', Water Science and Engineering. Hohai University. Production and hosting by Elsevier B. V., 3 (4), pp. 467-479. doi: $10.3882 /$ j.issn.1674-2370.2010.04.009.

[3] Chirisa, I. (2014). 'Building and urban planning in Zimbabwe with special reference to Harare: Putting needs, costs and sustainability in focus'. Consilience, (11), pp. 1-26.

[4] Davidson, N. C. (2014). 'How much wetland has the world lost? Long-term and recent trends in global wetland area'. Marine and Freshwater Research, 65 (10), pp. 934-941.

[5] Diaz, S. Demissew, S. Carabias, J. Joly, C. Lonsdale, M. Ash, N. and Bartuska, A. (2015) 'The IPBES Conceptual Framework-connecting nature and people', Current Opinion in Environmental Sustainability, (14), pp. 1-16.

[6] Dixon, M. J. R. Loh, J. Davidson, N. C. Beltrame, C. Freeman, R. and Walpole, M. (2016) 'Tracking global change in ecosystem area: The Wetland Extent Trends index', Biological Conservation. Elsevier, 193, pp. 27-35. doi: 10.1016/J.BIOCON.2015.10.023.

[7] Haines-Young, R., \& Potschin, M. (2012). Common international classification of ecosystem services (CICES, Version 4.1). European Environment Agency, pp. 33. Retrieved from https:/cices.eu/content/uploads/sites/8/2012/09/CICESV4_Final_ 26092012.pdf.

[8] Hartter, J. (2010). 'Resource use and ecosystem services in a forest park landscape'. Society and Natural Resources, 23 (3), pp. 207-223.

[9] Hu, S. Niu, Z. Chen, Y. Li, L. and Zhang, H. (2017) 'Science of the Total Environment Global wetlands: Potential distribution, wetland loss, and status', Science of the Total Environment. Elsevier B. V., pp. 1-9. doi: 10.1016/j.scitotenv.2017.02.001.

[10] Jogo, W. and Hassan, R. (2010). 'Balancing the use of wetlands for economic well-being and ecological security: The case of the Limpopo wetland in Southern Africa'. Ecological Economics, 69 (7), pp. 1569-1579.

[11] Jones, N. Clark, J. R. A. Panteli, M. and Proikaki, P. (2012) 'Author' s personal copy Local social capital and the acceptance of Protected Area policies: An empirical study of two Ramsar river delta ecosystems in northern Greece', Journal of Environmental Management (2012), (96), pp. 5563. doi: 10.1016/j.jenvman.2011.10.012.

[12] Kamins, A. O. Rowcliffe, J. M. Ntiamoa-Baidu, Y. Cunningham, A. A. Wood, J. L. and Restif, O. (2015). 'Characteristics and risk perceptions of Ghanaians potentially exposed to bat-borne zoonoses through bushmeat'. EcoHealth, 12 (1), pp. 104-120.

[13] Makunde, G. (2016) 'Challenges in Urban Development Control and Housing Provision: A Case of Epworth, Chitungwiza and Harare, Zimbabwe', International Journal of Technology and Management, 1 (1), pp. 1-10. 
[14] Marambanyika, T. and Beckedahl, H. (2016) 'The missing link between awareness and the implementation of wetland policy and legislation in communal areas of Zimbabwe The missing link between awareness and the implementation of wetland policy and legislation in communal areas of Zimbabwe', Wetlands Ecology and Management. Springer Netherlands, (March 2018). doi: 10.1007/s11273-016-9486-y.

[15] Matamanda, A. R., Chirisa, I., Mukamuri, B. B., Kaduwo, P., \& Mhlanga, M. (2018). Harare's deteriorating wetlands: Why sound policies and legislations are not enough. Case Studies in the Environment.

[16] Matiza, T. and Crafter, S. (1994) 'Wetland Ecology and Priorities for Conservation in Zimbabwe'. In Seminar on Wetlands Ecology and Priorities for Conservation in Zimbabwe (1992: Harare Kentucky Airport Hotel) IUCN

[17] Mbereko, A. (2012) 'Understanding socio-economic outcomes of Technological Innovations over access, use and management of natural resources in Zimbabwe: A case of Zungwi Vlei (Zvishavane District)'.

[18] Mujuru, M. McCrindle, R. I. Gurira, R. C. Zvinowanda, C. M. and Maree, J. (2012). 'Air Quality Monitoring in Metropolitan Harare. Zimbabwe'. J Environment Analytic Toxicol 2012, 2 (131), pp. 2161-0525.

[19] Mukwindidza, E. (2008). The implementation of environmental legislation in the Mutasa district of Zimbabwe. (Doctoral dissertation, University of South Africa).

[20] Mushore, T. D. Odindi, J., Dube, T. and Mutanga, O. (2017) 'Outdoor thermal discomfort analysis in Harare, Zimbabwe in Southern Africa Outdoor thermal discomfort analysis in Harare, Zimbabwe in Southern Africa', South African Geographical Journal. Routledge, pp. 1-18. doi: 10.1080/03736245.2017.1339630.

[21] Mutisi, L. (2014) 'An investigation into the contribution of housing developments to wetland degradation within the city of Harare, Zimbabwe. (Doctoral dissertation).', (August).

[22] Mutisi, L. and Nhamo, G. (2017) 'An Analysis of Water Quality in Belvedere North and the Epworth Wetlands of Harare, Zimbabwe', books.google.com. Available at: https://books.google.com/books?hl=en\&lr=\&id=pl1DDgAAQ BAJ\&oi $=$ fnd\&pg $=$ PA177\&dq $=$ Mutisi + and + Nhamo,$+2017+\mathrm{w}$ etlands\&ots=ulgBonDtLb\&sig=ObCV42ogD5Atrm1ROw81i U2HKGI (Accessed: 22 May 2019).

[23] Nyamadzawo, G. Wuta, M. Nyamangara, J. Nyamugafata, P. and Chirinda, N. (2015) 'Optimizing dambo (seasonal wetland) cultivation for climate change adaptation and sustainable crop production in the smallholder farming areas of Zimbabwe', International Journal of Agricultural Sustainability. Taylor \& Francis, 13 (1), pp. 23-39. doi: 10.1080/14735903.2013.863450.

[24] Rojas, C., Munizaga, J., Rojas, O., Martínez, C., \& Pino, J. (2019). 'Urban development versus wetland loss in a coastal Latin American city: Lessons for sustainable land use planning'. Land use policy, 80, pp. 47-56.

[25] Schuyt, K. D. (2005) 'Economic consequences of wetland degradation for local populations in Africa', 53 (2), pp. 177 190. doi: 10.1016/j.ecolecon.2004.08.003.

[26] Schuyt, K. D. and Brander, L. (2004) 'The Economic Values of the World's Wetlands'. World Wildlife Fund.

[27] Scholte, S. S. Todorova, M. van Teeffelen, A. J. and Verburg, P. H. (2016). 'Public support for wetland restoration: what is the link with ecosystem service values?' Wetlands, 36 (3), pp. 467-481.

[28] Shibia, M. G. (2010). 'Determinants of attitudes and perceptions on resource use and management of Marsabit National Reserve, Kenya'. Journal of Human Ecology, 30 (1), pp. 55-62.

[29] Shoshore, I. (2016). 'An assessment of a vlei ecosystem restoration process: Monavale Vlei, Harare'.

[30] Shwartz, A. Turbé, A. Simon, L. and Julliard, R. (2014). 'Enhancing urban biodiversity and its influence on citydwellers: An experiment'. Biological Conservation, 171, pp. $82-90$

[31] Sithole, A. and Goredema, B. (2013) 'Building in Wetlands to Meet the Housing Demand and Urban Growth in Harare Midlands State University Midlands State University', 3 (8), pp. 193-201.

[32] SWT. (2006). 'Saving the wetlands for people and the environment: a case study from Monavale Vlei, Zimbabwe'. Technical paper, Management Plan Workshop, 12th October 2006, Harare.

[33] Tsiko, R. G. and Togarepi, S. (2012). 'A situational analysis of waste management in Harare, Zimbabwe'. Journal of American Science, 8 (4), pp. 692-706.

[34] Tsveta, T. (2017) 'Assessing the contribution of the Environmental Management Agency (EMA) towards sound wetland management in harare urban'. Published dissertation, Midlands State University. 